\title{
Retraction Note: Constant water circulating ecological influence and remote English education system development based on sequence matching
}

\author{
Xiaohuan Zhang ${ }^{1}$
}

Published online: 3 November 2021

(c) Saudi Society for Geosciences 2021

Retraction Note: Arabian Journal of Geosciences (2021) 14: 1575

https://doi.org/10.1007/s12517-021-07966-8

The Editor-in-Chief and the Publisher have retracted this article because the content of this article is nonsensical. The peer review process was not carried out in accordance with the Publisher's peer review policy. The author has not responded to correspondence regarding this retraction.

The original article can be found online at https://doi.org/10.1007/ s12517-021-07966-8.

Xiaohuan Zhang

tiankongxiasunny@163.com

1 College English Department, Henan University,

Kaifeng 475000, Henan, China 